\section{Reducing the time from soup to nuts}

\author{
Everything in the Labour party's plan for the \\ NHS is subordinate to the need to increase \\ capacity and to bring down the waiting time \\ between seeing a GP and having an operation. \\ Nick Timmins reports
}

At election time some people (probably, in truth, a small and rather sad minority) pore over the parties' manifestos. They are often a pretty poor guide to the future. No one could possibly have gleaned from the Conservative manifesto for health in 1987 for example, that by 1992 the NHS would be operating an internal market. The big financial crisis late in 1987 that triggered the Conservatives' NHS review was just about visible; its outcome, to all but clairvoyants and those now granted the gift of hindsight, was not.

Equally, a newly landed Martian reading Labour's 1997 manifesto and looking at the NHS today would be entitled to wonder how on earth we got from there to here. That manifesto contained, for example, no mention of the National Institute for Clinical Excellence or the creation of an NHS inspectorate and a social care inspectorate, a clinical assessment authority, or a patient safety agency. A party that was later to introduce more central targets and a tougher performance management regime than any of its predecessors promised not to return to the "top down management of the 1970 s."

Added to that was a pledge to "end the Tory internal market." And there was a clear statement that Labour opposed "the privatisation of clinical services"-this from a party that today is introducing a string of immensely powerful market mechanisms into the NHS, along with a bunch of private providers whose turnover from clinical services will soon be worth more than $£ 2$ bn (\$3.8bn; €2.9bn) a year.

The lesson from this is not that politicians lie; rather it is that events (and events we can't currently foresee) can shape policy more than manifestos and that when one policy is plainly failing-in this case the "command and control" approach of Labour's first few years in office-governments will try another from the limited palette of policy prescriptions at their disposal.

So those wondering what a third Labour term will mean for the NHS have little need to read the manifesto. In any case, you would be better advised to read "the book" instead. This is the health service's 10 year plan which has pretty much reached its halfway stage, and its subsequent amendment and explication in a series of implementation documents (BMJ 2000;321:317).

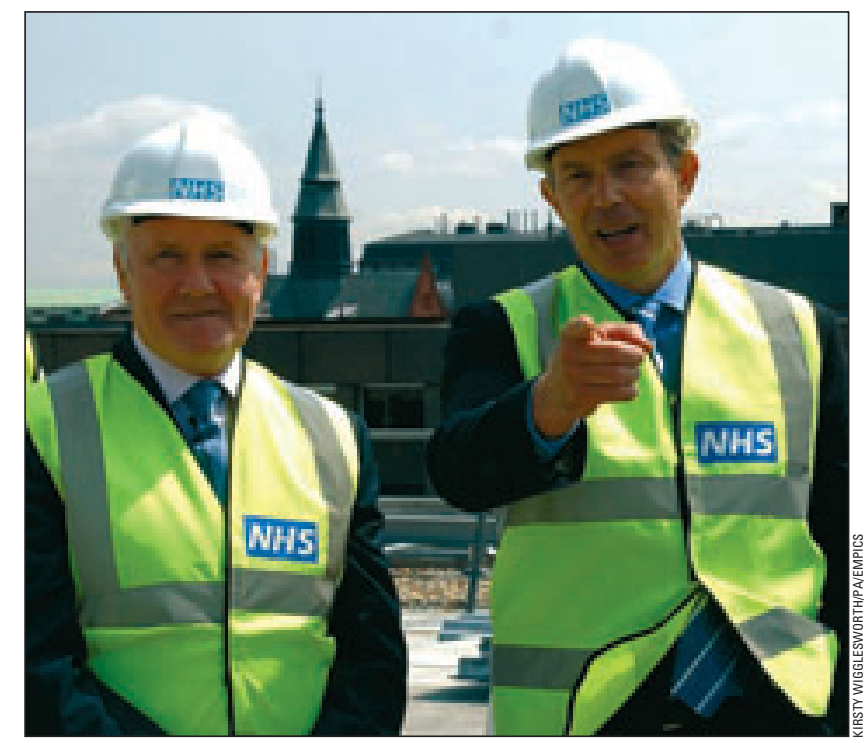
Blair) thinks that choice is not just for the middle classes

The manifesto does contain a few new minor nuggets. Elections would not be elections without a promise to cut bureaucracy, and Labour is promising to release a further $£ 250 \mathrm{~m}$ for frontline services through a piece of coded language that implies fewer strategic health authorities and primary care trusts over time. From a government that swears it is reducing the number of targets, the campaign has produced a couple of new ones on bowel providers (which could include the voluntary sector) can "add capacity or promote innovation."

For elective care, all this is aimed at getting the maximum wait from soup to nuts-from GP to operation-down to 18 weeks by 2008 , while significantly improving the management of chronic conditions. This is a set of changes that might genuinely allow ministers to claim a transformation in the NHS (or at least in the parts that attract most media attention).

Targets would be more
Health Secretary John Reid (pictured left, with Prime Minister Tony

and breast cancer and on the time taken to return cervical smears. It will consult on new laws to enforce higher hygiene standards in hospitals.

But these are sideshows in comparison with the main thrust of policy concerning competition (Labour prefers to use the word contestability), choice, and greater use of the private sector to deliver treatment, diagnostics, chronic care management, and anything else where new whether you believe that only the middle class will take advantage of choice or whether you accept the arguments of John Reid, the health secretary, that other people are perfectly capable of doing the same, perhaps with a little help. What it will mean for services also depends on how far patients actually exercise choice and on whether the mere threat of patients being able to move elsewhere leads, as Labour hopes, to services everywhere becoming more responsive.

But the fact that much talk exists in the health department about the need for "failure regimes" shows that hospitals that do not respond will find themselves in deep financial trouble, with ministers openly admitting that some services could close. Add to that the return of GP commissioning, and some big shifts might occur in how and where services are provided.

On public health, Labour promises legislation that will stop short of a total ban on smoking in public places, rather than the Tories' voluntary code and the Liberal Democrats' outright ban. Legislation on nutritional standards for school meals is promised, as is clearer food labelling and restrictions on promoting food and drinks high in fat, salt, and sugar to children.

As for money, it is clear that under either Labour or the Tories the record $7 \%$ a year increases in NHS spending of recent years will come to an end after 2007-8. Spending by then will be around the EU average. Capital investment in hospitals, GPs' premises, and community facilities looks set to continue, not least through the private finance initiative. But both Labour and the Tories argue that, in revenue terms, by 2008 a large amount of the "catch up" that the NHS needed will have been achieved.

The Tory plans for the two years beyond 2008 point to a $4 \%$ increase in real terms-a little above the long term trend since 1948 of 3\%. The Wanless report suggested that an increase of between $4.4 \%$ and $5.7 \%$ a year will be needed between 2008 and 2012 (BMJ 2002;324:998). The word in Whitehall, for what it is worth, is that the Treasury is contemplating $4 \%$ growth in real terms if Labour wins. The health department, unsurprisingly, will be bidding for more.

Nicholas Timmins public policy editor, Financial Times 